\title{
Rapid Measurement of Diesel Engine Oil Quality By Near Infrared Spectroscopy (NIRS)
}

\author{
Xing Zhi-Na*, Wang Jiu-Xiang and Qu Jun
}

Department of Airborne Vehicle Engineering, Naval Aeronautical and Astronautical University, Yantai 264001, Shandong, China

\begin{abstract}
A near infrared spectroscopy (NIRS) rapid measurement was applied to diesel engine oil quality. $100^{\circ} \mathrm{C}$ kinematic viscosity change rate and flash point of $\mathrm{CD} 15 \mathrm{~W}$ lubricant were built by the means of interval and combination partial least (icPLS). The calibration correlation coefficient $\left(\mathrm{R}_{\text {validation }}^{2}\right.$ ) and least prediction standard error (SEP) of these models were $0.8954,2.24 \%$ and $0.7729,2^{\circ} \mathrm{C}$ respectively. A $t$-test $(\alpha=0.05)$ showed that the NIR model had an accuracy equivalent to that of the standard method in the analysis for both $100^{\circ} \mathrm{C}$ kinematic viscosity and flash point. It was indicated that NIRS method was a new analysis means, which could take place of traditional method, for rapid measurement of diesel engine oil quality.
\end{abstract}

Keywords: Near infrared spectroscopy (NIRS), diesel engine oil, $100^{\circ} \mathrm{C}$ kinematic viscosity change rate, flash point, rapid measure.

\section{INTRODUCTION}

Lubricants play a key role in extending the working life of moving machines. Lubricant monitoring is an effective safeguard technology for the working state monitoring and maintenance of engine and transmission. Periodic monitoring of the chemical condition of lubricant is necessary when it has degraded to a point to which it no longer performs its proper function and may also be an indicator for abnormal operation of the engine. Highly degraded oils have the potential to damage lubricated system components and shorten the life expectancy of the engine or transmission. Then lubricant monitoring provides the foundation of maintenance decision. Some lubricant or equipment producters will recommend some oil-change criterion in order to protect equipment. Nowadays China have built multi national standard of oil-change criterion for lubricant and engine oil [1]. That's to say, lubricant quality is the basic safeguard for normal working of all movable components and the key of ascertain oil-change time [2].

Heavy duty vehicle always works in the quite bad environment such as high dust and high moisture. So that its engine and transmission system wear seriously. The lubricant quality monitoring of heavy duty vehicle has a rather important applying value. Among the monitoring criterion, $100^{\circ} \mathrm{C}$ kinematic viscosity change rate and flash point are the direct reflection of the engine deterioration. And they are the main criterions in the GB/T 7607 oilchange criterion of diesel engine oil [3]. The traditional methods to determine the above criterion, ASTM D445 and ASTM D92, are very time-consuming, requiring

*Address correspondence to this author at the NO.188 ErMaLu, Zhifu district, Yantai, 264001, Shandong, China;

E-mail: zhnxing2008@163.com sophisticated equipment and specific instrument. Besides, the using engine oil which is the black ropy liquid is very difficult to test. The test error is rather large otherwise the analyst is a senior operator. The traditional methods can't determine these two criterions in line further more [4]. In short, it does not meet the need of a rapid, easy to use, selective, and sensitive analytical technique.

Near-infrared spectroscopy (NIRS) is an easy, rapid and nondestructive technique applied in many areas such as food, pharmacy and petroleum [5-10]. The study of determination kinematic viscosity and water of lubricant by NIRS have been reported [11, 12]. Therefore, NIRS should be a selective method to determine these two criterions of engine oil.

The aim of this paper is to obtain the mathematic relationship and regression equation of NIR spectrum absorption and $100^{\circ} \mathrm{C}$ kinematic viscosity change rate or flash point by NIRS. Then a rapid determination method of diesel engine oil quality is to be developed.

\section{MATERIALS AND METHODS}

\subsection{Instrumentation}

All samples were tested for $100^{\circ} \mathrm{C}$ kinematic viscosity on a kinematic viscosity instrument (Model HCR 1043, Haicr instruments and meters Co. Ltd., Zhen Zhou, China) and for flash point on a open cup flash point instrument (Model SHD-3K, Reshang instruments Co. Ltd., Da Qing, China). Then $100^{\circ} \mathrm{C}$ kinematic viscosity change rate is calculated from equation (1):

$\eta=\frac{v_{1}-v_{2}}{v_{2}} \times 100$

Where $v_{1}$ is the determination value of used oil, $v_{2}$ is the determination value of new oil. 
Table 1. Oil Laboratory Reference Data of CD 15W Engine for NIR Model Building

\begin{tabular}{|c|c|c|c|c|c|c|c|}
\hline Sample NO. & $\begin{array}{c}100^{\circ} \mathrm{C} \text { kinematic viscosity } \\
\text { change rate, } \%\end{array}$ & Flash point, ${ }^{\circ} \mathrm{C}$ & Remark & Sample NO. & $\begin{array}{l}100^{\circ} \mathrm{C} \text { kinematic viscosity } \\
\text { change rate, } \%\end{array}$ & Flash point, ${ }^{\circ} \mathrm{C}$ & Remark \\
\hline 1 & 0 & 233 & New oil & 16 & 25.70 & 229 & Used oil \\
\hline 2 & 19.52 & 229 & Used oil & 17 & 26.87 & 229 & Used oil \\
\hline 3 & 17.18 & 233 & Used oil & 18 & 20.89 & 229 & Used oil \\
\hline 4 & 10.17 & 233 & Used oil & 19 & 24.47 & 229 & Used oil \\
\hline 5 & 18.97 & 230 & Used oil & 20 & 19.38 & 231 & Used oil \\
\hline 6 & 21.79 & 231 & Used oil & 21 & 25.77 & 229 & Used oil \\
\hline 7 & 14.50 & 229 & Used oil & 22 & 23.51 & 229 & Used oil \\
\hline 8 & 20.14 & 238 & Used oil & 23 & 23.99 & 241 & Used oil \\
\hline 9 & 16.49 & 231 & Used oil & 24 & 30.31 & 223 & Used oil \\
\hline 10 & 9.76 & 233 & Used oil & 25 & 20.89 & 229 & Used oil \\
\hline 11 & 15.33 & 237 & Used oil & 26 & 24.47 & 229 & Used oil \\
\hline 12 & 23.99 & 241 & Used oil & 27 & 25.70 & 229 & Used oil \\
\hline 13 & 25.70 & 234 & Used oil & 28 & 26.87 & 229 & Used oil \\
\hline 14 & 27.22 & 223 & Used oil & 29 & 19.38 & 231 & Used oil \\
\hline 15 & 30.31 & 229 & Used oil & 30 & 25.77 & 229 & Used oil \\
\hline
\end{tabular}

These were the laboratory reference methods for analysis of samples employed as standards for NIRS calibration development.

NIR spectra were acquired using the NIR spectrometer (Model SupNIR-2600, Juguang science and technology Co. Ltd., Hang Zhou, China) with a transmission InGaSe detector in a useable wavelength range of 1,000 nm -1,800 $\mathrm{nm}$. All measurements were performed using air as reference.

\subsection{Sample Preparation and Data Collection}

The diesel engine oil model was CD 15W. The certain heavy duty vehicle using diesel was chosen to take samples. 29 samples with $500 \mathrm{~km}$ interval mileage were obtained by tracking a same vehicle. Then the sample set with 30 samples was consistent of the above 29 samples and a new engine oil. 30 samples were divided into 22 samples as a calibration set and 8 samples as a validation set by K-S method.

The laboratory reference data (Table 1) were obtained by the standard methods.

\subsection{Spectra Collection}

All measurements were performed using a $5 \mathrm{~cm}$ pathlength quartz cuvette at sample temperature $\left(25^{\circ} \mathrm{C} \pm 0.5^{\circ} \mathrm{C}\right)$. Fig. (1) showed the NIR curve of diesel engine oil.

\section{RESULTS AND DISCUSSION}

\subsection{Methodology}

Partial least-squares (PLS) is among the most widely used for processing spectral data and relating spectroscopic signals (predictor variables) to target variables (analyte concentrations, usually). Interval and combination partial least (icPLS) [13] was applied to select the efficient spectral regions that provided the lowest prediction error. The actual modeling course was as follows. Firstly, spectra of calibration set were divided into $\mathrm{n}$ regions by a perfect window. PLS Model was built on every spectra region respectively. The optimal PLS model of every region was obtained by the means of cross validation standard error

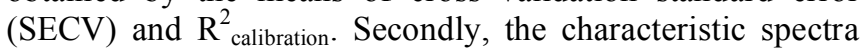
regions were added from the region with the least SECV and

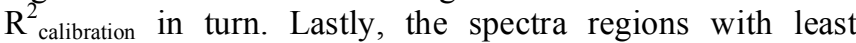
prediction standard error (SEP) were chosen to combine to built the prediction model by judging of SEP.

The accuracy of these two NIRS models was analyzed by the statistic analysis of $t$-test respectively. A set of data were built by selecting $z_{\mathrm{i}}=y_{\mathrm{i}}-x_{\mathrm{i}}$ according to the requirement of $t$ test. The mathematical expectation value is 0 . The $t$ value was calculated from equation (2):

$t=(\bar{z}-\mu) \frac{\sqrt{n}}{S}$

Where $x_{\mathrm{i}}$ is the reference value of the No. $i$ sample in validation set, $y_{\mathrm{i}}$ is the model prediction value of the No. $i$ sample in validation set, $z_{\mathrm{i}}$ is the difference of the model prediction value and reference value of the No. $i$ sample in validation set, $t$ is the statistical probability at the $95 \%$ confidence, $z$ is the average of $z, \mu$ is the mathematical expectation value of $z, n$ is the sample number of validation set, $S$ is the prediction standard error of model. 


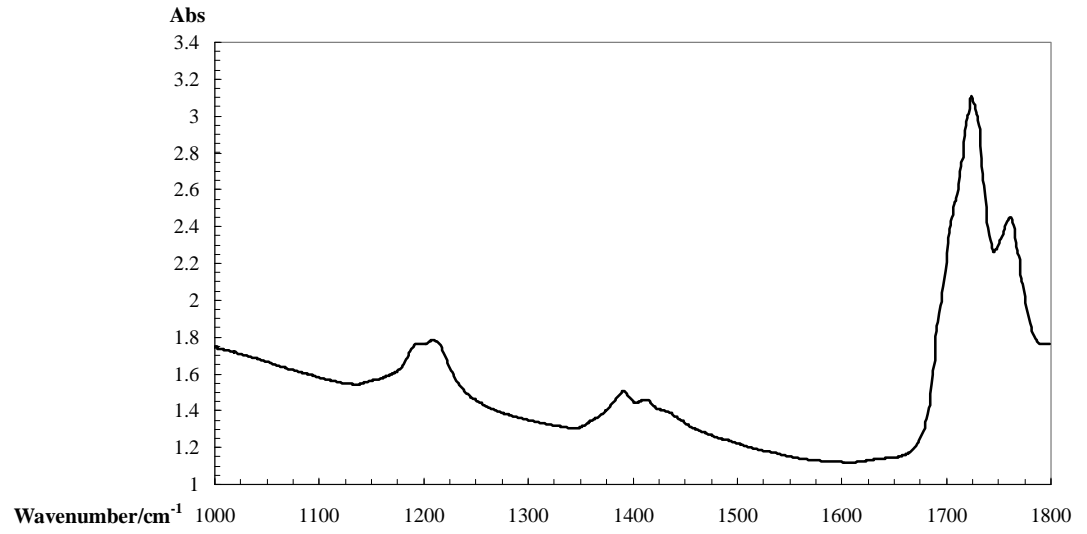

Fig. (1). CD 15W diesel engine oil NIR spectrum.

Table 2. icPLS Model Parameter of CD 15W/40 Engine Oil

\begin{tabular}{|l|c|c|c|c|}
\hline Model Name & Spectra Pretreatment & Optimal Factor & SECV & $\boldsymbol{R}_{\text {calibration }}$ \\
\hline \hline $\begin{array}{l}100^{\circ} \text { C kinematic } \\
\text { viscosity change rate }\end{array}$ & $\begin{array}{c}5 \text { points smoothing, centering, } \\
\text { first derivative (30) } \\
\text { Orthogonal signal calibration (45) }\end{array}$ & 5 & $2.11 \%$ & 0.916 \\
\hline Flash point & $\begin{array}{c}\text { centering, } \\
\text { Savitzky-Golay derivative }\end{array}$ & 8 & $1.023{ }^{\circ} \mathrm{C}$ & 0.842 \\
\hline
\end{tabular}

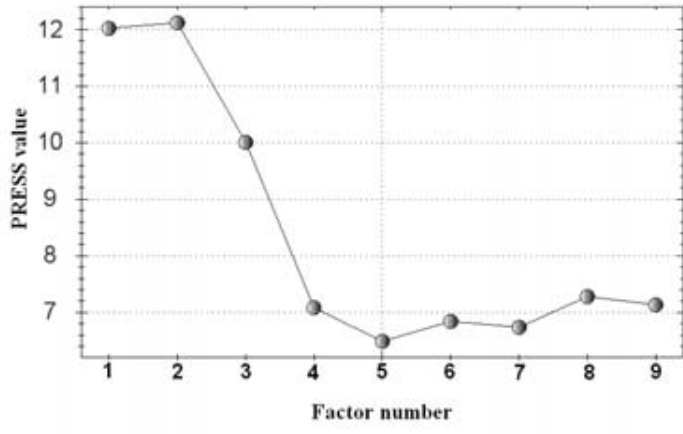

a $\cdot 100^{\circ} \mathrm{C}$ kinematic viscosity change rate

Fig. (2). Calibration model PRESS curves.

\subsection{NIRS Model Built and Validation}

The icPLS models parameters of $100^{\circ} \mathrm{C}$ kinematic viscosity change rate and flash point were listed in Table $\mathbf{2}$. And the PRESS curves were shown in Fig. (2). $R_{\text {calibration in }}^{2}$ Table 2 presented these two NIR models had good correlation with the criterions.

The 8 samples belonging to the validation set were used to test the accuracy of the calibration model. A comparison of the values reported by the NIR method with those of the laboratory reference method was presented in Table 3. The correlation between the reference values and the predicted values received from the NIRS calibration model was shown in Fig. (3).

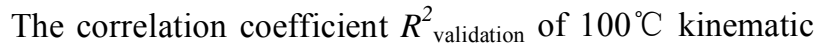
viscosity change rate and flash point were 0.8954 and 0.7729 respectively. SEP of those were $2.24 \%$ and $2{ }^{\circ} \mathrm{C}$ respectively.

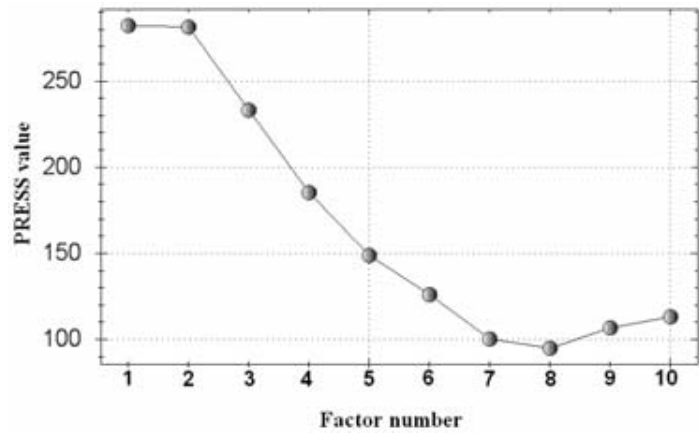

b . Flash point

It was presented that these two NIRS models had a good precision.

The difference between NIRS and laboratory reference of these two criterions were statistically significant at the $95 \%$ confidence $(\alpha=0.05)$ level respectively because $t_{\text {calculation }}$ values of $100^{\circ} \mathrm{C}$ kinematic viscosity change rate was 1.200 less than 2.365 and that of flash point was 1.194 less than 2.776. That's to say that NIRS method can replace the traditional method to analyze $100^{\circ} \mathrm{C}$ kinematic viscosity change rate and flash point.

\section{CONCLUSION}

NIRS has the distinct advantages of being much fasteronce initial calibration is done-requiring less or no chemicals at all and no sample preparation.Results here showed that NIRS has great potential to predict the physical criterions of engine oil. NIRS provided accurate estimation 
Table 3. Comparison of Results Determined by NIRS and Laboratory Reference Method

\begin{tabular}{|c|c|c|c|c|c|c|}
\hline NO. & \multicolumn{3}{|c|}{$100^{\circ} \mathrm{C}$ Kinematic Viscosity Change Rate (\%) } & \multicolumn{3}{|c|}{ Flash Point $\left({ }^{\circ} \mathbf{C}\right)$} \\
\hline 1 & 10.17 & 13.71 & -3.54 & 233 & 230 & 3 \\
\hline 2 & 18.97 & 16.54 & 2.43 & 230 & 227 & 3 \\
\hline 3 & 21.79 & 19.97 & 1.82 & 231 & 231 & 0 \\
\hline 5 & 30.31 & 31.70 & -1.39 & 229 & 230 & -1 \\
\hline 6 & 19.38 & 18.94 & 0.44 & 231 & 231 & 0 \\
\hline 7 & 24.77 & 22.46 & 2.31 & 229 & 227 & 2 \\
\hline 8 & 9.87 & 11.12 & -1.25 & 237 & 235 & 2 \\
\hline
\end{tabular}

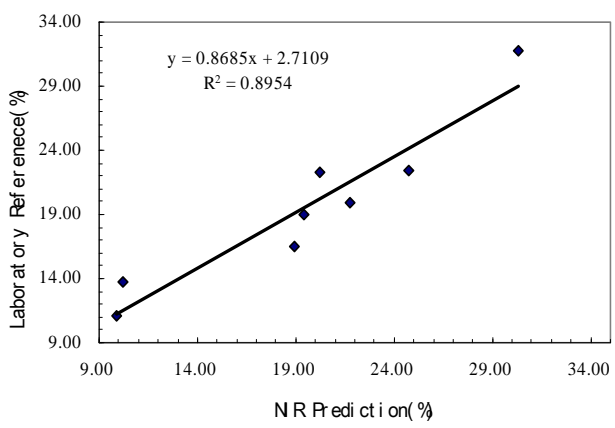

a $\cdot 100^{\circ} \mathrm{C}$ kinematic viscosity change rate

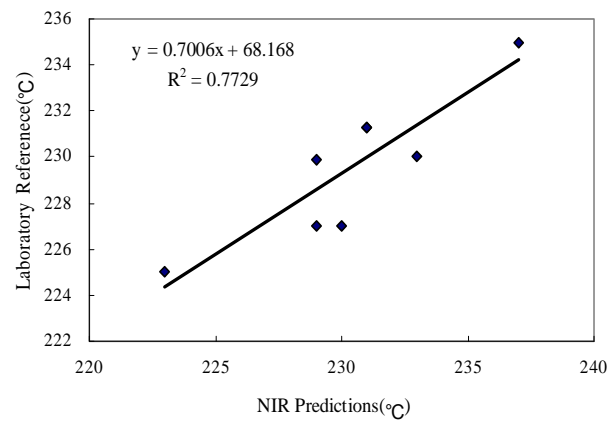

b . Flash point

Fig. (3). NIR prediction versus reference determination

of $100^{\circ} \mathrm{C}$ kinematic viscosity change rate and flash point. The results obtained encourage the study of these techniques to develop models to determine other physical and chemical properties of lubricant base oils.

\section{CONFLICT OF INTEREST}

Declared none.

\section{ACKNOWLEDGEMENT}

Declared none.

\section{REFERENCES}

[1] Z. J. Guan, Lubricant and Equipment Failure Diagnosis Technology, China Petrochemical Press: China, 2007, p. 84.

[2] J.S. Olferta, J.P.R. Symondsb, and N. Collingsa, "The effective density and fractal dimension of particles emitted from a light-duty diesel vehicle with a diesel oxidation catalyst", Journal of Aerosol Science, vol. 38, no.1, pp. 66, 2007.

[3] X. Zhou, and D. X. Shi, GB/T 7607-2002, Criteria for change of engine oil used in diesel engine, Standards Press of China: Beijing 2008.

[4] J. Vanhanen, M. Rinkio, J. Aumanen, J. Korppi-Tommola, E. Kolehmainen, T. Kerkkänen, and P. Törmä, "Characterization of used mineral oil condition by spectroscopic techniques", Journal of Applied Optics, vol. 43, no. 24, pp. 4718-4722, 2004.

[5] M. Pilar Doradoa, S. Pinzia, and A. de Haro, "Visible and NIR spectroscopy to assess biodiesel quality: Determination of alcohol and glycerol traces", Journal of Fuel, vol. 90, no. 6, pp. 2321, 2011.

[6] P. Lei, and J. Bauhus, "Use of near-infrared reflectance spectroscopy to predict species composition in tree fine-root mixtures", Journal of Plant Soil, vol. 333, no. 1-2, pp. 93-103, 2010.

[7] M. Blanco, J. Cruz and M. Bautista, "Development of a univariate calibration model for pharmaceutical analysis based on NIR spectra", Journal of Analytical and Bioanalytical Chemistry, vol. 392, no. 7-8, pp. 1367, 2008.

[8] L.E. Rodriguez-Saonaa, F.S. Fryb, and M.A. McLaughlin, "Rapid analysis of sugars in fruit juices by FT-NIR spectroscopy", Journal Carbohydrate Research, vol. 336, no. 1, pp. 63, 2001.

[9] P. Qian, G. Q. Sun, and C. Z. Zhang, "A novel fuzzy neural network method for diesel quantitative analysis with near infrared spectroscopy", Journal of Spectroscopy and Spectral Analysis, vol. 28 , no. 12, pp. 2851, 2008.

[10] M. Tatlier, and H.K. Cigizoglu, "A artificial neural network methods for the estimation of zeolitemolar compositions that form from different reaction mixtures", Journal of Computers and Chemical Engineering, vol. 30, no. 1, pp. 137, 2005.

[11] Y. Zhang, L. L. Jiang, and D. Wu, " Non-invasive measurement of water content in engine oil using visible and near infrared spectroscopy", Journal of Spectroscopy and Spectral Analysis, vol. 30, no. 8, pp. 2111, 2010. 
[12] A. R. Caneca, M. F. Pimentel, and R. K. H. Galvao, "Assessment of infrared spectroscopy and multivariate techniques for monitoring the service condition of diesel-engine lubricating oils", Journal of Talanta, vol. 70, no. 2, pp. 344, 2006.
[13] Z. N. Xing, J. X. Wang, and G. Shen, “Applying improved partial least squares methods to aviation kerosene determination by nearinfrared spectroscopy", Journal of Acta Armamentarii, vol. 31, no. 8 , pp. 1106,2010

Received: April 26, 2012

(C) Zhi-Na et al.; Licensee Bentham Open.

This is an open access article licensed under the terms of the Creative Commons Attribution Non-Commercial License (http://creativecommons.org/licenses/by-nc/3.0/) which permits unrestricted, non-commercial use, distribution and reproduction in any medium, provided the work is properly cited. 